\title{
The Demographic Transition and the Emergence of Sustained Economic Growth*
}

\author{
Oded Galor ${ }^{\dagger}$
}

September 22, 2004

\begin{abstract}
The demographic transition that swept the world in the course of the last century has been identified as one of the prime forces in the transition from stagnation to growth. The unprecedented increase in population growth during the early stages of industrialization was ultimately reversed and the demographic transition brought about a significant reduction in fertility rates and population growth in various regions of the world, enabling economies to convert a larger share of the fruits of factor accumulation and technological progress into growth of income per capita. This paper examines various mechanisms that have been proposed as possible triggers for the demographic transition, assessing their empirical validity, and their potential role in the transition from stagnation to growth.

Keywords: Growth, Technological Progress, Demographic Transition, Human Capital, Evolution, Malthusian Stagnation.

JEL classification Numbers: O11, O14, O33, O40, J11, J13.
\end{abstract}

*Acknowledgements. The author wishes to thank Gregory Clark, Matthias Doepke, Moshe Hazan, Sebnem Kalemli-Ozcan, Omer Moav, and David Weil for valuable discussions. This research is supported by NSF Grant SES-0004304.

${ }^{\dagger}$ Department of Economics, Brown University, Providence RI 02912, USA. e-mail: Oded Galor@brown.edu 


\section{Introduction}

The transition from stagnation to growth and the associated phenomenon of the great divergence have been the subject of an intensive research in the growth literature in recent years. The inconsistency of exogenous and endogenous neoclassical growth models with some of the most fundamental features of process of development, induced growth theorists to advance a unified growth theory that captures in a single framework the epoch of Malthusian stagnation, the contemporary era of sustained economic growth, and the fundamental driving forces of the recent transition between these distinct regimes.

The understanding of the contemporary growth process is fragile and incomplete unless growth theory would be based on proper micro-foundations that reflect the qualitative aspects of the growth process and its central driving forces over most of human existence. Moreover, a comprehensive understanding of the hurdles faced by less developed economies in reaching a state of sustained economic growth would be futile unless the factors that prompted the transition of the currently developed economies into a state of sustained economic growth would be identified and their implications modified to account for the differences in the growth structure of less developed economies in an interdependent world.

Unified growth theory, first advanced by Galor and Weil $(1999,2000)$, suggests that the transition from stagnation to growth is an inevitable by-product of the inherent Malthusian interaction between population and technology, and its ultimate impact on the demand for human capital and thereby on the onset of the demographic transition. Variations in the timing of the transition across countries and regions reflect initial differences in geographical factors and historical accidents and their manifestation in variations in institutional, demographic, and cultural factors, trade patterns, colonial status, and public policy.

The demographic transition that swept the world in the course of the last century has been identified as one of the prime forces in the movement from an epoch of stagnation to a state of sustained economic growth. It brought about a significant reduction in fertility rates and population growth in various regions of the world, enabling economies to convert a larger share of the fruits of factor accumulation and technological progress into growth of income per capita

This paper examines various mechanisms that have been proposed as possible triggers 
for the demographic transition, assessing their empirical validity, and their potential role in the transition from stagnation to growth.

\section{Historical Evidence}

The evolution of economies over most of human history was marked by Malthusian stagnation. Technological progress and population growth were miniscule by modern standards and the average growth rate of income per capita in various regions of the world was even slower due to the offsetting effect of population growth on the expansion of resources per capita. In the past two centuries, in contrast, the pace of technological progress increased significantly in association with the process of industrialization. Various regions of the world economy departed from the Malthusian trap and initially experienced a considerable rise in the growth rates of income per capita and population. Unlike episodes of technological progress in the pre-Industrial Revolution era that failed to generate sustained economic growth, the increasing role of human capital in the production process in the second phase of the Industrial Revolution ultimately prompted a demographic transition, liberating the gains in productivity from the counterbalancing effects of population growth. The decline in population growth and the associated advancement in technological progress and human capital formation paved the way for the emergence of the modern state of sustained economic growth.

The evolution of population growth in the world economy has been non-monotonic. The growth of world population was sluggish during the Malthusian epoch, creeping at an average annual rate of about $0.1 \%$ over the years 0-1820 (Maddison (2003)). The Western European take-off along with that of the Western Offshoots (i.e., United States, Canada, Australia and New Zealand) brought about a sharp increase in population growth in these regions and consequently in the world as a whole. The annual average rate of population growth in the world increased gradually reaching $0.8 \%$ in the years 1870-1913. The delayed take-off of less developed regions and the significant increase in their income per capita generated a further gradual increase in the rate of population growth in the world, despite the decline in population growth in Western Europe and the Western Offshoots, reaching a high level of $1.92 \%$ per year in the period 19501973. Ultimately, however, the onset of the demographic transition in less developed economies in the second half of the 20th century, reduced population growth to an average rate of about 
$1.63 \%$ per year in the $1973-1998$ period.

The timing of the demographic transition differed significantly across regions. The reduction in population growth occurred in Western Europe, the Western Offshoots, and Eastern Europe towards the end of the 19th century and in the beginning of the 20th century, whereas Latin America and Asia experienced a decline in the rate of population growth only in the last decades of the 20th century. Africa's population growth, in contrast, has been rising steadily, although this pattern is likely to reverse in the near future due to the decline in total fertility rate in this region since the 1980 s.

The demographic transition in Western Europe occurred towards the turn of the 19th century. A sharp reduction in fertility took place simultaneously in several countries in the 1870s, and resulted in a more than a $30 \%$ decline in fertility rates within a 50 year period. As depicted in Figure 1, over the period 1875-1920, Crude Birth Rates declined by $44 \%$ in England, $37 \%$ in Germany, 32\% in Sweden and Finland, and 26\% in France, (where the decline in fertility started already in the second half of the 18 th century). ${ }^{1}$
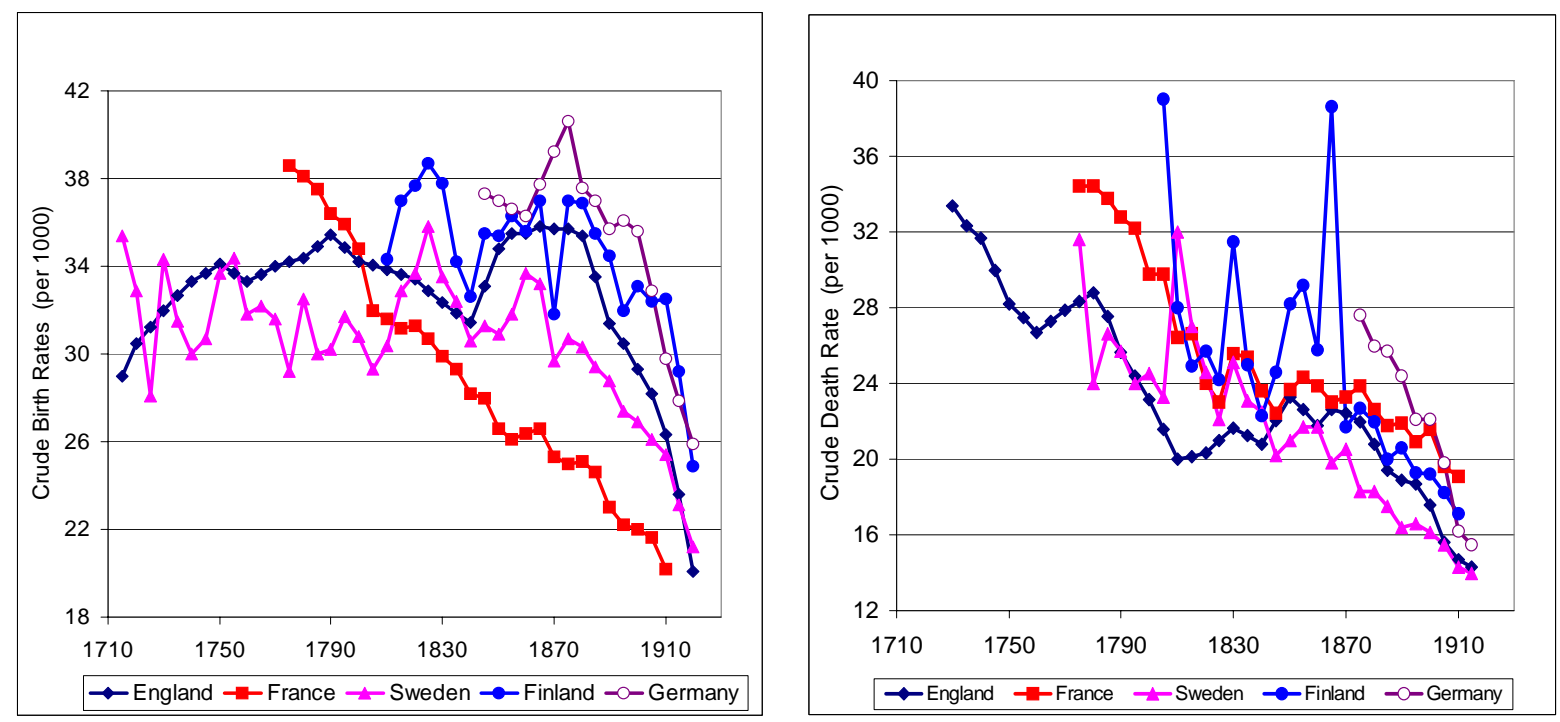

Figure 1. The Decline in Fertility and Mortality in Western Europe:

Source: Andorka (1978)

The mortality decline preceded the decline in fertility rates in a large number of countries in the world, with the notable exceptions of France and the United States. The decline in mortality rates preceded the decline in fertility rates in Western European countries and it

\footnotetext{
${ }^{1}$ Coale and Treadway (1986) find that a $10 \%$ decline in fertility rates was completed in $59 \%$ of all European countries in the time period 1890-1920.
} 
began in England nearly 140 years prior to the decline in fertility and in Sweden and Finland approximately 100 years prior to the decline in fertility. The decline in fertility during the demographic transition outpaced the decline in mortality rates and brought about a decline in the number of children who survived to their reproduction age (e.g., Kuzynski (1969)).

A similar sequence of events characterizes the pattern of mortality and fertility decline in less developed regions. Total Fertility Rate over the period 1960-1999 plummeted from 6 to 2.7 in Latin America and from 6.14 to 3.14 in Asia. Even in Africa the Total Fertility Rate declined moderately from 6.55 in 1960 to 5.0 in 1999. Moreover, a sharp decline in infant mortality rates corresponded to the decline in fertility rates in many of the countries in these regions.

\section{Assessment of Theories of the Demographic Transition}

Theories of the demographic transition attempt to capture the determinants of the significant reduction in fertility rates and population growth that characterized the world in the past century, enabling economies to convert an increasing share of the benefits of factor accumulation and technological progress into growth of output per capita via a reduction of the dilution of the stock of capital and land, enhancement of investment in the human capital, and changes in the age distribution of the population, temporarily increasing the size of the labor force relative to the population as a whole.

\subsection{The Decline in Infant and Child Mortality}

The decline in infant and child mortality rates that preceded the decline in fertility rates in many countries, with the notable exceptions of France and the US, has been demographers' favorite explanation for the onset of the decline in fertility in the course of the demographic transition. Nevertheless, it appears that this viewpoint is inconsistent with historical evidence. While it is highly plausible that mortality rates were among the factors that affected the level of total fertility rates along human history, historical evidence does not lend credence to the argument that the decline in mortality rates accounts for the reversal of the positive historical trend between income and fertility.

As demonstrated in Figure 1, the mortality decline in Western Europe started nearly a century prior to the decline in fertility and was associated initially with increasing fertility rates in some countries and non-decreasing fertility rates in other countries. In particular, as 
demonstrated in Figure 2, the decline in mortality started in England in the 1730s and was accompanied by a steady increase in fertility rates until 1820. The significant rise in income per capita in the Post-Malthusian Regime increased the desirable number of surviving offspring and thus, despite the decline in mortality rates, fertility increased significantly so as to reach this higher desirable level of surviving offspring. The decline in fertility during the demographic transition occurred in a period in which this pattern of increased income per capita (and its potential positive effect on fertility) was intensified, while the pattern of declining mortality (and its adverse effect on fertility) maintained the trend that existed in the 140 years that preceded the demographic transition. Thus in the absence of the intervention of a third factor fertility would have risen further. ${ }^{2}$ The reversal in the fertility patterns in England as well as other Western European countries in the 1870s suggests therefore that the demographic transition was prompted by a different universal force than the decline in infant and child mortality. ${ }^{3}$
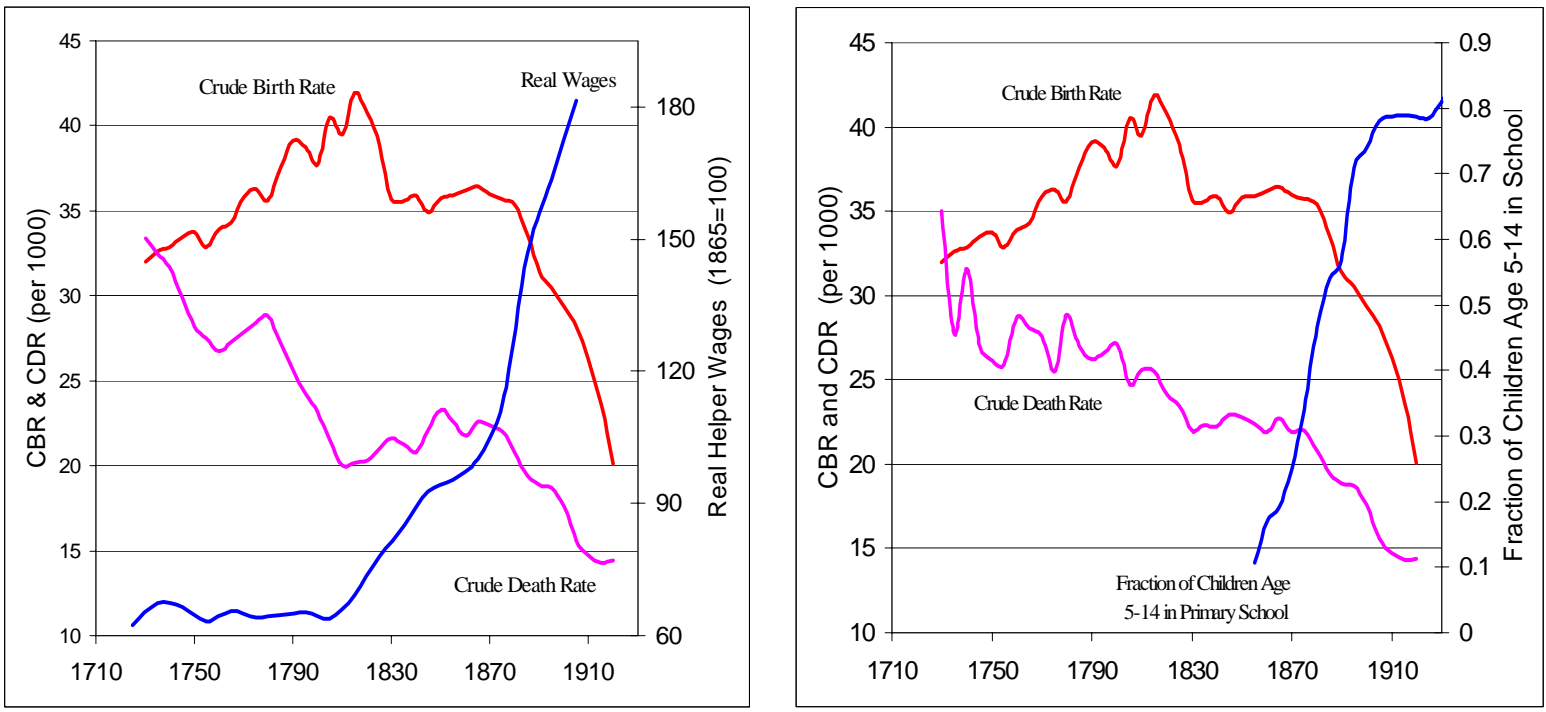

Figure 2. Sources of the demographic Transition: England 1720-1930

Source: Wrigley and Schofield (1981), Flora et al. (1983), Clark (2002), and Andorka (1978)

Furthermore, most relevant from an economic point of view is the cause of the reduction in net fertility (i.e. the number of children reaching adulthood). The decline in the number

\footnotetext{
${ }^{2}$ One could argue that the decline in mortality was not internalized into the decision of households who had difficulties separating a temporary decline from a permanent one. This argument is highly implausible given the fact that mortality declined monotonically for nearly 140 years prior to the demographic transition. It is inconceivable that six generations of household did not update information about mortality rates in their immediate surrounding, while keeping the collective memories about mortality rates two centuries earlier.

${ }^{3}$ A quantitative analysis by Doepke (2005) supports the viewpoint that a decline in infant mortality rates was not the trigger for the decline in net fertility during the demographic transition. based on data from England in the time period 1861-1951. Similarly the insignificance of the mortality decline in the decline in fertility during the demographic transition is established in the quantitative analysis of Fernandez-Vilaverde (2004).
} 
of surviving offspring that was observed during the demographic transition is unlikely to follow from mortality decline. Mortality decline would have led to a reduction in the number of surviving offspring if the following set implausible of conditions would be met: ${ }^{4}$ (i) There exists a significant precautionary demand for children, i.e., individuals are significantly risk averse with respect to their expected number of surviving offspring and they hold a buffer stock of children in a high mortality environment. (Highly improbable from an evolutionary perspective). (ii) Risk aversion with respect to consumption is smaller than risk aversion with respect to fertility. (Evolutionary theory would suggest the opposite). (iii) Sequential fertility (i.e., replacement of non-surviving children) is modest. ${ }^{5}$ (iv) Parental resources saved from the reduction in the number of children that do not survive to adulthood do not lead to a rise in fertility. ${ }^{6}$

\subsection{The Rise in the Level of Income Per Capita}

The rise in income per capita prior to the demographic transition has led some researchers to argue that the demographic transition was triggered by the rise in income per capita and its asymmetric effects on households income and on the opportunity cost of raising children. Becker (1981) advances the argument that the decline in fertility in the course of the demographic transition is a by-product of the rise in income per capita that preceded the demographic transition. He argues that the rise in income induced a fertility decline because the positive income effect on fertility that was generated by the rise in wages was dominated by the negative substitution effect that was brought about by the rising opportunity cost of children. Similarly, he argues that the income elasticity with respect to child quality is greater than that with respect to child quantity, and hence a rise in income led to a decline in fertility along with a rise in the investment in each child.

This theory, however, is counter-factual. ${ }^{7}$ It suggests that the timing of the demographic

\footnotetext{
${ }^{4}$ Kalemli-Ozcan (2002) generates a reduction in net fertility in reaction to a decline in mortality assuming (implicitly) that all these implausible conditions are satisfied. Eckstein et al. (1999) argue, based on conditions (iii) and (iv) as well as specific interactions between mortality, wages, and the return to human capital, that mortality decline played a role in the demographic transition in Sweden.

${ }^{5}$ Doepke (2005) shows that regardless of the degree of risk aversion, the feasibility of sequential fertility is sufficient to preclude the decline in net fertility in reaction to a decline in mortality.

${ }^{6} \mathrm{An}$ additional force that operates against the decline in the number of surviving offspring is the physiological constraint on the feasible number of birth per woman. If this constraint is binding for some households in a high mortality regime, a reduction in mortality would operate towards an increase the number of surviving offspring.

${ }^{7}$ For instance, a quantitative analysis of the demographic transition in England, conducted by FernandezVilaverde (2004), demonstrates that in contrast to Becker's theory, a rise in income would have resulted in an increase in fertility rates, rather than in the observed decline in fertility.
} 
transition across countries in similar stages of development would reflect differences in income per capita. However, remarkably, as depicted in Figure 1, the decline in fertility occurred in the same decade across Western European countries that differed significantly in their income per capita. In 1870, on the eve of the demographic transition, England was the richest country in the world, with a GDP per capita of $\$ 3191$. In contrast, Germany that experienced the decline in fertility in the same years as England, had in 1870 a GDP per capita of only $\$ 1821$ (i.e., 57\% of that of England). Sweden's GDP per capita of $\$ 1664$ in 1870 was $48 \%$ of that of England, and Finland's GDP per capita of $\$ 1140$ in 1870 was only $36 \%$ of that of England, but their demographic transitions occurred in the same decade as well. ${ }^{8}$ The simultaneity of the demographic transition across Western European countries that differed significantly in their income per capita suggests that the high level of income that was reached by Western Europeans countries in the Post-Malthusian regime had a very limited role in the demographic transition. ${ }^{9}$

Interestingly, and consistent with Galor and Weil (2000) and Galor and Moav (2002), that underlined the critical role of the acceleration in technological progress and its effect on the demand for human capital in the demographic transition, despite the large differences in the levels of income per capita across European countries that experiences the demographic transition in the same time period, the growth rates of income per capita of these European countries were rather similar during their demographic transition, ranging from $1.9 \%$ per year over the period 1870-1913 in the UK, $2.12 \%$ in Norway, $2.17 \%$ in Sweden, to $2.87 \%$ in Germany.

\subsection{The Rise in the Demand for Human Capital}

\subsubsection{The Main Mechanism}

The gradual rise in the demand for human capital in the second phase of the Industrial Revolution (and in the process of industrialization of less developed economies) and its close association with the timing of the demographic transitions, has led researchers to argue that the increasing role of human capital in the production process induced households to increase investment in the human capital of their offspring, ultimately leading to the onset of the demographic transition.

Galor and Weil $(1999,2000)$, argue that the acceleration in the rate of technological

\footnotetext{
${ }^{8}$ Source: Maddison (2001). GDP per capita is measured in 1990 international dollars.

${ }^{9}$ Furthermore, cross-section evidence within countries suggest that the elasticity of the number of surviving offspring with respect to wage income was positive prior to the demographic transition (e.g., Clark (2003)), in contrast to Becker's argument that would require a hump-shaped relationship.
} 
progress gradually increased the demand for human capital in the second phase of the Industrial Revolution, inducing parents to invest in the human capital of their offspring. The increase in the rate of technological progress and the associated increase in the demand for human capital brought about two effects on population growth. On the one hand, improved technology eased households' budget constraints and provided more resources for the quality as well as the quantity of children. On the other hand, it induced a reallocation of these increased resources toward child quality. In the early stages of the transition from the Malthusian regime, the effect of technological progress on parental income dominated, and the population growth rate as well as the average quality increased. Ultimately, further increases in the rate of technological progress that were stimulated by human capital accumulation induced a reduction in fertility rates, generating a demographic transition in which the rate of population growth declined along with an increase in the average level of education. Thus, consistent with historical evidence, the theory suggests that prior to the demographic transition, population growth increased along with investment in human capital, whereas the demographic transition brought about a decline in population growth along with a further increase in human capital formation. ${ }^{10}$

Galor and Weil's theory suggests that a universal rise in the demand for human capital in the second phase of the Industrial Revolution and the simultaneous increase in educational attainment across Western European countries generated the observed simultaneous onset of the demographic transition across Western European countries that differed significantly in their levels of income per capita. In particular, as depicted in Figure 2, the demographic transition in England was associated with a significant increase in the investment in child quality as reflected by years of schooling.

Evidence about the evolution of the return to human capital over this period are scarce and controversial. They do not indicate that the skill premium increased markedly in Europe over the course of the 19th century (e.g., Clark 2003). One can argue that the lack of clear evidence about the increase in the return to human capital over this period is an indication for the absence of a significant increase in the demand for human capital. This partial equilibrium argument, however, is flawed. The return to human capital is an equilibrium price that is

\footnotetext{
${ }^{10}$ Quantitative evidence provided by Greenwood and Seshadri (2002) is supportive of the role of the rise in the demand for skilled labor (via technological progress in an industrial, skilled-intensive, sector that is faster than that in an unskilled-intensive, agricultural sector) in the demographic transition in the US.
} 
affected both by the demand and the supply of human capital. Technological progress in the second phase of the Industrial Revolution brought about an increase in the demand for human capital, and indeed, in the absence of a supply response, one would have expected an increase in the return to human capital. However, the significant increase in schooling that took place in the 19th century, and in particular the introduction of public education that lowered the cost of education, generated a significant increase in the supply of educated workers. Some of this supply response was a direct reaction of the increase in the demand for human capital, and thus may only operate to partially offset the increase in the return to human capital. However, the removal of the adverse effect of credit constraints on the acquisition of human capital (e.g., Galor and Zeira 1993), as reflected by the introduction of public education, generated an additional force that increased the supply of educated labor and operated towards a reduction in the return to human capital. ${ }^{11}$

\subsubsection{Reinforcing Mechanisms}

The Decline in Child Labor. The effect of the rise in the demand for human capital on the reduction in the desirable number of surviving offspring was magnified via its adverse effect on child labor. It gradually increased the wage differential between parental labor and child labor inducing parents to reduce the number of their children and to further invest in their quality (Hazan and Berdugo 2002). Moreover, the rise in the importance of human capital in the production process induced industrialists to support education reforms (Galor and Moav 2003, 2004) and thus laws that abolish child labor (Doepke and Zilibotti 2003), triggering a reduction in child labor and thus in fertility. ${ }^{12}$

The Rise in Life Expectancy. The impact of the increase in the demand for human capital on the decline in the desirable number of surviving offspring may have been reinforced by the rise in life expectancy. The decline in mortality rates in developed countries since the 18th century and the recent decline in mortality rates in less developed countries corresponded to

\footnotetext{
${ }^{11}$ This argument is supported indirectly by contemporary evidence about a higher rate of returns to human capital in less developed economies than in developed economies (Psacharopoulos and Patrinos 2002). The greater prevalence of credit markets imperfections and other barriers for the acquisition of skills in less developed economies generated only a partial supply response to industrial demand for human capital, contributing to this differential in the skill premium. The effect of inequality in the presence of credit constraints in discussed in Dahan and Tsiddon (1988).

${ }^{12}$ Doepke (2004) provides quantitative evidence that suggests that indeed, child labor law played an important role in the demographic transition.
} 
a gradual increase in life expectancy. Life expectancy increased in Western Europe during the 19th and the 20th century from 36 in 1820 to 46 in 1900, 67 in 1950 and 78 in 1999, and in less developed economies during the 20th century.

Despite the gradual rise in life expectancy prior to the demographic transition, investment in human capital was rather insignificant as long as a technological demand for human capital had not emerged. Similarly, the rise in life expectancy in less developed regions in the first half of the 20th century has not generated a significant increase in education and a demographic transition. The technologically based rise in the demand for human capital during the second phase of the Industrial Revolution and the rise in the expected length of productive life has increased the potential rate of return to investments in children's human capital, and thus reinforced and complemented the inducement for investment in education and the associated reduction in fertility rates. ${ }^{13}$

Natural Selection and the Evolution of Preference for Offspring's Quality. The impact of the increase in the demand for human capital on the decline in the desirable number of surviving offspring may have been magnified by cultural or genetic evolution in the attitude of individuals toward child quality. Galor and Moav (2002) propose that during the epoch of Malthusian stagnation that characterized most of human existence, individuals with a higher valuation for offspring quality (in the context of the quantity-quality, survival strategies) gained an evolutionary advantage and their representation in the population gradually increased. The agricultural revolution facilitated the division of labor and fostered trade relationships across individuals and communities, enhancing the complexity of human interaction and raising the return to human capital. Moreover, the evolution of the human brain in the transition to Homo sapiens and the complementarity between brain capacity and the reward for human capital has increased the evolutionary optimal investment in the quality of offspring. The distribution of valuation for quality lagged behind the evolutionary optimal level and individuals with traits of higher valuation for their offspring's quality generated higher income and, in the Malthusian epoch when income was positively associated with aggregate resources allocated to child rearing, a larger number of offspring. Thus, the trait of higher valuation for quality gained the evolutionary advantage, and the Malthusian pressure gradually increased the representation of

\footnotetext{
${ }^{13}$ See Galor and Weil (1999), Hazan and Zoabi (2004), Moav (2005) and Soares (2005).
} 
individuals whose preferences were biased towards child quality.

This mechanism is consistent with the observed gradual rise in literacy rates prior to the Industrial Revolution. It suggests that the increase in the investment in human capital prior to the Industrial Revolution was a reflection of changes in the composition of preference for quality in the population that stimulated investment in human capital, prior to the increase in the demand for human capital in the second phase of the Industrial Revolution.

This evolutionary process was reinforced by its interaction with economic forces. As the fraction of individuals with high valuation for quality increased, technological progress intensified, raising the rate of return to human capital. The increase in the rate of return to human capital along with the increase in the bias towards quality in the population reinforced the substitution towards child quality, setting the stage for a more rapid decline in fertility along with a significant increase in investment in human capital.

\subsection{The Decline in the Gender Gap}

The decline in the gender gap in the last two centuries is an alternative mechanism that could have triggered a demographic transition and human capital formation. The rise in women's relative wages and women's relative education in the last two centuries and its potential impact on the rise in female labor force participation and the associated decline in fertility rates have been the center of another theory of the demographic transition. ${ }^{14}$

A theory based upon the decline in the gender wage gap and the associated with a decline in fertility was explored by Galor and Weil $(1996,1999)$. They argue that technological progress and capital accumulation complemented mental-intensive tasks and substituted for physicalintensive tasks in the industrial production process. In light of the comparative physiological advantage of men in physical-intensive tasks and women in mental-intensive tasks, the demand for women's labor input gradually increased in the industrial sector, decreasing monotonically the wage deferential between men and women. In early stages of industrialization, wages of men and women increased, but the rise in female's relative wages was insufficient to induce a significant increase in women's labor force participation. Fertility, therefore increased due to the

\footnotetext{
${ }^{14}$ The rise in women's relative wages and literacy rates along with declining fertility rates has been observed in a large number of developed and less developed economies. In particular, this pattern was observed in the US during the period 1800-1930 (See, U.S. Bureau of the Census, (1975), Goldin (1990) and Hernandez (2000)). Moreover, literacy rates among women in England grew from $76 \%$ of those among men in 1840 to about $100 \%$ in 1900 (Cipolla(1969)).
} 
income effect that was generated by the rise in men's absolute wages. ${ }^{15}$ Ultimately, however, the rise in women's relative wages was sufficient to induce a significant increase in labor force participation. It increased the cost of child rearing proportionally more than households income, generating a decline in fertility and a shift from stagnation to growth. ${ }^{16}$

\subsection{Other Theories}

The Old-Age Security Hypothesis. The old-age security hypothesis has been proposed as an additional mechanism for the onset of the demographic transition. It suggests that in the absence of capital markets that permit intertemporal lending and borrowing, children are assets that permit parents to smooth consumption over their lifetime. ${ }^{17}$ The process of development and the establishment of capital markets reduce this motivation for rearing children, contributing to the demographic transition.

Although old-age support is a plausible element that may affect the level of fertility, it appears as a minor force. The importance of the decline in the role of children as assets in the onset of the demographic transition is questionable. The rise in fertility rates prior to the demographic transition, in a period of improvements in the credit markets, raises doubts about the significance of the mechanism. Furthermore, cross-section evidence in the pre-demographic transition era indicates that wealthier individuals, that presumably had a better access to credit markets, had a larger number of surviving offspring (e.g., Lee 1987 and Clark 2003). ${ }^{18}$

Exogenous Shocks - Luck. Becker, Murphy and Tamura (1990) advance a theory that emphasizes the role of a major exogenous shock in triggering the demographic transition, underlying the role of luck in the determination of the relative timing of the demographic transition across nations and the wealth of nations. They argue that a major shock shifted

\footnotetext{
${ }^{15}$ The U-shaped pattern of female labor force participation in the process of industrialization follows from the coexistence of an industrial sector and a non-modern production sector that does not fully rival with child rearing. Women's marginal product in non-modern sector was not affected by capital accumulation in the industrial sector, while women's potential wages in the modern sector increased. In the early process of industrialization, therefore, capital accumulation increased labor productivity in the industrial sector, family income increased via men's wages, while female wages, based on the production of market goods in the home sector did not change. Fertility increased due to the income effect and female labor force participation fell. Once capital accumulation and technological progress increases female relative wages sufficiently, capital accumulation raised women's relative wages, inducing a rise in female labor force participation in the industrial sector and reducing fertility.

${ }^{16}$ Similarly, Lagerloef (2003b) argues that the process of development permitted a gradual improvement in the relative level of female education, raising the opportunity cost of children and initiating a fertility decline and a transition to sustained economic growth.

${ }^{17}$ See Caldwell (1976) for earlier studies and Boldrin and Jones (2002) for a recent quantitative analysis.

${ }^{18}$ Moreover, examples of species in nature in which offspring support their parent in old age are very rare.
} 
economies from the low-output high-fertility steady-state equilibrium towards the high-output low-fertility steady-state equilibrium, triggering a demographic transition. This theory suffers from critical deficiencies in the micro-structure. ${ }^{19}$ Moreover, it generates predictions that are inconsistent with the evidence. In particular, in contrast to existing evidence that shows that the process of industrialization and the associated increase in income per capita was accompanied by sharp increase in population growth, prior to their decline in the course of the demographic transition, a major shock that would shift the economy from the basin of attraction of a highfertility to a low-fertility steady-state equilibrium would generate, counterfactually, a monotonic decline in fertility rates along with a simultaneous rise in income per capita.

\section{Concluding Remarks}

The demographic transitions that swept the world in the course of the last century has been identified as one of the prime forces in the transition from stagnation to growth. It brought about significant reduction in fertility rates and population growth in various regions of the world, enabling economies to convert a larger share of the fruits of factor accumulation and technological progress into growth of income per capita. Various mechanisms have been proposed as possible triggers for the demographic transition, and thus as a catalyst in the transition from stagnation to growth. Empirical evidence, however, suggests that the increasing role of human capital in the production process in the second phase of the Industrial Revolution was the central force behind the demographic transition. Unlike episodes of technological progress in the preIndustrial Revolution era that failed to generate sustained economic growth, the onset of the demographic transition liberated the gains in productivity from the counterbalancing effects of population growth paving the way for human capital formation and the emergence of the modern state of sustained economic growth.

\footnotetext{
${ }^{19}$ Multiplicity of equilibria in their model is generated by the implausible assumption that the return to education increases with the aggregate level of education in society. Moreover, their "Malthusian" steady-state has none of the features of a Malthusian equilibrium: (a) in the absence of technological change population growth rate is not at the reproduction level, (b) counter-factually population growth in their "Malthusian" steady-state is higher than the that in the beginning of the demographic transition, (c) a small positive shock to income when the economy is in the "Malthusian" steady-state initially decreases fertility.
} 


\section{References}

[1] Becker, Gary.S. (1981). A Treatise on the Family (Harvard University Press, Cambridge).

[2] Becker, Gary.S. Kevin. Murphy and Robert. Tamura (1990). "Human Capital, Fertility, and Economic Growth," Journal of Political Economy, October 98: S12-S37.

[3] Boldrin, Michelle.and Larry Jones (2002). "Mortality, Fertility, and Saving in a Malthusian Economy," Review of Economic Dynamics 5: 775-814.

[4] Caldwell, John C. (1976). "Toward a Restatement of Demographic Transition Theory", Population and Development Review 2: 321-66.

[5] Chesnais, Jean-Claude (1992). "The Demographic Transition: Stages, Patterns and Economic Implications" (Clarendon Press, Oxford).

[6] Cipolla, Carlo M. (1969).. Literacy and Development in the West (Penguin Books, Harmondsworth, Middlesex)

[7] Clark, Gregory (2003). "The Condition of the Working-Class in England, 1200-2000: Magna Carta to Tony Blair", UC Davis.

[8] Clark, Gregory. and Gillian Hamilton (2003). "Survival of the Fittest? Capital, Human Capital, and Reproduction in European Society before the Industrial Revolution" UC Davis.

[9] Coale, Ansley J. and Roy. Treadway (1986). "A Summary of the Changing Distribution of Overall Fertility, Marital Fertility, and the Proportion Married in the Provinces of Europe", in: A J. Coale and S. Watkins, eds., The Decline of Fertility in Europe (Princeton University Press, Princeton).

[10] Dahan, Momi.and Daniel Tsiddon (1998). "Demographic Transition, Income Distribution, and Economic Growth", Journal of Economic Growth 3: 29-52.

[11] Doepke, Matthias (2004). "Accounting for Fertility Decline During the Transition to Growth", Journal of Economic Growth 9: 347-383

[12] Doepke, Matthias (2005). "Child Mortality and Fertility Decline: Does the Barro-Becker Model Fit the Facts?," Journal of Population Economics (forthcoming).

[13] Doepke, Matthias and Fabrizio Zilibotti (2003). "The Macroeconomics of Child Labor Regulation," IIES, Stockholm University.

[14] Eckstein, Zvi, Pedro S. Mira and Kenneth. I. Wolpin (1999). "A Quantitative Analysis of Swedish Fertility Dynamics:1751-1990." Review of Economic Dynamics 2: 137-165.

[15] Fernandez-Villaverde, Jesus (2004). "Was Malthus Right? Economic Growth and Population Dynamics", University of Pennsylvania.

[16] Flora, Peter, Jens Alber, Richard Eichenberg, Jurgen Kohl, Franz Kraus, Winfried Pfenning and Kurt Seebohm (1983). State, Economy and Society in Western Europe 1815-1975, Vol. I. (St. James Press, Chicago).

[17] Galor, Oded and Omer. Moav. (2002). "Natural Selection and the Origin of Economic Growth", Quarterly Journal of Economics 117: 1133-1192.

[18] Galor, Oded and Omer. Moav (2003). "Das Human Kapital: A Theory of the Demise of the Class Structure", Brown University.

[19] Galor, Oded and Omer. Moav. (2004). "From Physical to Human Capital Accumulation: Inequality and the Process of Development", Review of Economic Studies, 71. 
[20] Galor, Oded and David.N. Weil. (1996). "The Gender Gap, Fertility, and Growth", American Economic Review 86: 374-387.

[21] Galor, Oded and David.N. Weil. (1999). "From Malthusian Stagnation to Modern Growth", American Economic Review, 89: 150-154.

[22] Galor, Oded and David.N. Weil. (2000). "Population, Technology and Growth: From the Malthusian regime to the Demographic Transition", American Economic Review 110: 806828.

[23] Galor, Oded and Joseph. Zeira. (1993). "Income Distribution and Macroeconomics", Review of Economic Studies 60: 35-52.

[24] Goldin, Claudia. (1990). Understanding The Gender Gap: An Economic History of American Women. (Oxford University Press, New York)

[25] Greenwood, Jeremy and Ananth. Seshadri.(2002). "The U.S. Demographic Transition," American Economic Review 92: 153-159.

[26] Hazan, Moshe and Benjamin Berdugo.(2002). "Child Labor, Fertility and Economic Growth," Economic Journal, 112: 810-828.

[27] Hazan, Moshe.and Hosni Zoabi (2004). "Does Longevity Cause Growth,?” Hebrew University.

[28] Hernandez, Donald. J. (2000). Trends in the Well Being of America's Children and Youth. U.S. Bureau of the Census.

[29] U.S. Bureau of the Census (1975). Historical Statistics of the United States: Colonial Times to 1970, Part 1, (Washington D.C.).

[30] Kalemli-Ozcan, Sebnem (2002). "Does the Mortality Decline Promote Economic Growth," Journal of Economic Growth 7: 411-439.

[31] Kuzynski, Robert R. (1969). The Measurement of Population Growth, (Gordon and Breach Science Publishers, New York).

[32] Lagerloef, Nils-Petter.(2003a). "From Malthus to Modern Growth: The Three Regimes Revisited", International Economic Review 44: 755-777.

[33] Lagerloef, Nils-Petter. (2003b). "Gender Equality and Long-Run Growth," Journal of Economic Growth, 8: 403-426.

[34] Lee, Ronald.D. (1997). "Population Dynamics: Equilibrium, Disequilibrium, and Consequences of Fluctuations", in: O. Stark and M. Rosenzweig, eds., The Handbook of Population and Family Economics (Elsevier, Amsterdam).

[35] Maddison, Angus (2003). The World Economy: Historical Statistics CD-ROM (OECD, Paris).

[36] Moav, Omer (2005). "Cheap Children and the Persistence of Poverty", Economic Journal, 114:

[37] Mokyr, Joel. (2002). The Gifts of Athena: Historical Origins of the Knowledge Economy (Princeton University Press, Princeton).

[38] Soares, Rodrigo. R. (2005). "Mortality Reductions, Educational Attainment, and Fertility Choice," American Economic Review, forthcoming.

[39] Wrigley, E.Anthony.and Roger.S. Schofield (1981). The Population History of England 15411871: A Reconstruction (Harvard University Press, Cambridge). 